\title{
Jogos, espetáculos e competições na Palestina romana
}

\author{
Vagner Carvalheiro Porto*
}

PORTO, V.C. Jogos, espetáculos e competições na Palestina romana. R. Museu Arq. Etn., 29:119-136, 2017.

Resumo: Este texto tem por objetivo apresentar os jogos e competições que eram realizados na Palestina romana. Poderão ser observadas nas linhas que seguem as diversas construções de Herodes, o Grande, também conhecido como rei-construtor, no campo dos espetáculos. Destacam-se a Liberalitas Augusti, generosidade, de Herodes, e a inserção da romanitas na região, a partir, principalmente, de suas obras. A documentação textual e a documentação material ditarão os caminhos do conhecimento acerca das estruturas relacionadas aos jogos na Palestina romana, seja por seus teatros, anfiteatros e hipódromos, seja pelos hábitos culturais daí advindos.

Palavras-chave: Jogos; Competições; Espetáculos; Herodes, o Grande; Palestina Romana.

\section{Introdução}

Doder, propaganda e jogos possuem

uma estreita relação em se tratando do universo romano, e este texto pretende demonstrar - observando-se a documentação arqueológica e as fontes históricas, principalmente Flavio Josefo - que na região da Palestina romana não haveria de ser diferente. Os romanos se utilizaram desse expediente e fortaleceram mais e mais os vínculos possíveis entre seus jogos e o poder estabelecido. Dessa forma, a partir da percepção de que num momento festivo ou ritualístico definem várias formas de interação e de relacionamento social, criando-se hierarquias e estruturando-se formas de poder, os espetáculos passaram a ser vistos como um

* Professor do Museu de Arqueologia e Etnologia da Universidade de São Paulo (MAE/USP).

<vagnerporto@usp.br> importante objeto de estudo da história e da arqueologia por excelência.

Ana Teresa Marques Gonçalves (2013: 229), ao citar Jean-Marie Apostolidès, afirma que o espetáculo é uma necessidade intrinsecamente associada ao exercício do poder: o monarca deve deslumbrar o povo. O cerimonial associado ao monarca tem por função tornar visível o imaginário do corpo simbólico. Veremos nas linhas que seguem como Herodes, o Grande, rei da Judeia, se valeu enormemente desse expediente e introduziu a humanitas romana na região da Palestina, principalmente por meio das construções que empreendeu no campo dos espetáculos, dos jogos e das competições.

\section{Liberalitas Augusti de Herodes}

O reinado de Herodes, o rei-construtor, é caracterizado pela larga escala de construções que mudaram dramaticamente a face da antiga Palestina. Nomeado rei da Judeia pelo 
senado romano, Herodes iniciou, planejou e construiu uma gama quase inquantificável de edifícios em seu reino. Suas construções eram proporcionais ao estilo de vida cerimonial em seus palácios, assim como os edifícios públicos que ele construíra para os habitantes de muitas cidades na antiga Palestina, algumas das quais ele mesmo havia fundado.

O envolvimento pessoal do rei nesses projetos resultou de seu interesse particular por arquitetura, de sua forte ambição e de sua necessidade de estabelecer uma base para a dinastia real tanto em seu reinado quanto no exterior, além, é claro, de expressar lealdade a seus patronos e amigos em Roma.

Os projetos monumentais das edificações de Herodes ampliaram, sem dúvida, os horizontes antigos da Palestina, introduzindo para a população local uma construção inovadora, seguindo o planejamento e a decoração à moda dos ricos de Roma e, por consequência, influenciando o estilo de vida e os hábitos cotidianos da população local, seja em seu culto, sociedade, comércio, economia, cultura ou lazer.

O rei-construtor investiu grandes somas de dinheiro, energia e pensamento na monumentalização de seu reino e também contribuiu com seus próprios recursos para a construção de novas estruturas ou para a renovação de edificações antigas para além de seu reino, em cidades próximas e em lugares distantes do outro lado do mar.

Zeev Weiss, importante especialista no tema, nos informa que Herodes construiu salões, pórticos, templos e mercados em Tiro e Beritos; em Biblos ele renovou as muralhas da cidade; e em Laodiceia ele construiu um aqueduto. Suas contribuições chegaram até mesmo a ajudar o povo de Antioquia, Rodes e Quios, bem como de Nicópolis, que o imperador fundou perto de Actium ${ }^{1}$ e onde Herodes erigiu a maioria de suas construções públicas (Weiss 2014: 12).

No artigo que publicamos para o dossiê Etnicidades da revista Phoînix (Porto 2018),

1 Em português Áccio ou Ácio. Neste trabalho optamos por manter o vernáculo latino. é apresentada uma discussão que procura demonstrar a generosidade de Herodes, o Grande, relacionada às instituições romanas de congiaria e donativa. Lá afirmamos que

Augusto adotara essa prática, estabelecendo para todo o Império um padrão de generosidade (Liberalitas Augusti) que foi imitado por seus sucessores. Nesse sentido, a magnanimidade geral de Herodes pode ter sido uma imitação da própria politica de benevolência inaugurada por Augusto. (Porto 2018: 146)

Natália Frazão José (2014: 83) nos recorda que Augusto nunca deixou de promover o culto ao Divino Júlio, pois estava ciente da importância da divinização de César tanto em Roma quanto nos territórios estrangeiros, erguendo em sua homenagem templos, realizando jogos e promovendo ritos. A autora sugere que Augusto buscava demonstrar a imagem de pietas de Cesar, destacando seu caráter divino. Essa atitude de Augusto influenciou sobremaneira Herodes, sua noção de humanitas romana e suas realizações no Oriente.

A liberalitas Augusti do rei foi reconhecida por muitos, incluindo o imperador e Agripa, e, sem dúvida, teve um efeito profundo sobre os recebedores de suas benfeitorias. $\mathrm{O}$ historiador Flávio Josefo observou: "a extensão do reino de Herodes não era igual à sua magnanimidade" (Josephus 1998: 16.141, tradução minha). O escopo e a grandeza dos projetos de construção de Herodes foram muito além dos de qualquer outro rei cliente em seu tempo; eles foram superados apenas por Augusto e provavelmente igualados apenas por seu amigo Marcus Agripa.

$\mathrm{O}$ amor do rei pela cultura grega e romana, juntamente com seu desejo de integrar seu reino de maneira política, social e cultural ao Império Romano, também o levou a estabelecer jogos e a construir estruturas para abrigar performances, competições, corridas e outros tipos de eventos. Durante suas muitas campanhas pelo império - em Alexandria, nas cidades da Ásia Menor, em diversas ilhas gregas - e em várias de suas visitas 
a Roma, Herodes entrou em contato com a cultura helênica e foi exposto a uma variedade de competições - aquelas realizadas no formato grego e outras em conformidade com a tradição romana. As obras de Josefo (Guerra dos judeus contra os romanos, Antiguidades Judaicas e Vida de Josefo) e muitos achados arqueológicos corroboram que a maioria das energias do rei nesse e em outros projetos de construção foram direcionadas para atividades em seu próprio reino. Weiss nos diz que devido à generosidade e ao amor pelo esporte, Herodes também construíra edifícios e doara fundos para financiar jogos em outras cidades (Weiss 2014: 12). Nesse quesito, nosso entendimento de generosidade segue muito mais o sentido de liberalitas Augusti, em que congiaria e donativa, como discorremos anteriormente, referiam-se a doações monetárias e benesses de toda sorte, principalmente vinculadas aos jogos e espetáculos. Nesse sentido, a humanitas romana se espalhava para todo o lado Oriental do Império.

Flavio Josefo nos lembra que Herodes construiu ginásios em Trípoli, Damasco e Ptolemais; em Cos financiou a manutenção da sede anual do ginasiarca ${ }^{2}$; em Sídon e Damasco ele construiu teatros; e em Olímpia o rei ofereceu um grande presente para reviver os jogos que decaíram devido à falta de dinheiro (Josephus 1997: 1.422-428).

Entre os projetos de construção herodianos conhecidos fora de seu reino, que são reconhecidos apenas em fontes literárias, estão as ruínas do teatro em Damasco, ao sul da cidade, localizado na Via Recta, não muito longe do templo de Júpiter, que foi construído naquele mesmo tempo (Weiss 2014: 12-13).

No Oriente helenístico, de Alexandre, o Grande, até Pompeu e até o reinado de Herodes, apenas alguns edifícios foram

2 A magistratura e a direção efetiva do colégio eram do "chefe do ginásio", o ginasiarca, que se ocupava de organizar a estrutura, mas não da instrução dos efebos, da qual é encarregado um prático. Geralmente era escolhido entre os mais abastados da cidade, e seu título era um dos mais honoríficos na época helenística. Em casos fortuitos, o ginasiarca poderia ser ajudado em sua tarefa por um adjunto, o hipoginasiarca, que se ocuparia principalmente da administração efébica. erguidos para competições e espetáculos. Segundo John H. Humphrey, em seu trabalho Roman circuses: arenas for chariot racing, Ptolomeu I Sóter teria construído um hipódromo em Alexandria conhecido como o Lageion (Humphrey 1986: 505-506).

Zeev Weiss (2014: 13) nos informa que Malalas ${ }^{3}$ escreveu dizendo que Quintius Marcius Rex, procônsul da Cilícia, construiu um hipódromo em Antioquia com seus próprios recursos em $67 \mathrm{AEC}$, e que pouco depois Júlio César construiu um teatro na cidade $^{4}$. Josefo menciona um hipódromo em Damasco no primeiro século AEC (Josephus 1998: 13.389).

Estes são exemplos isolados de edifícios para entretenimento de massa, em seus estágios iniciais, que não tiveram impacto algum sobre os hábitos culturais da população local ou sobre os padrões de construção ou a paisagem arquitetônica das cidades na antiga Palestina. Herodes, o Grande, deveria, portanto, ser considerado um pioneiro que introduziu espetáculos e competições públicas de grande escala no Oriente Romano, revolucionando os hábitos recreativos das populações locais, ao mesmo tempo em que estabelecia novas tendências em seu ambiente físico e cultural.

\section{A evidência literária e arqueológica}

Informações sobre as celebrações que Herodes inaugurou em seu reino, os edifícios que ele ergueu e os espetáculos e as competições que instituiu são selecionadas principalmente das crônicas de Flávio Josefo. Nascido na antiga Palestina e um dos líderes da revolta contra Roma, Josefo passou para o lado romano após a queda de Jotapata em 67

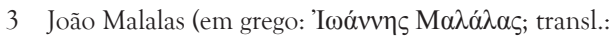
Ioannes Malalas; 491-578 EC) foi um cronista bizantino de Antioquia. Malalas é provavelmente uma palavra siríaca para reitor ou orador; foi aplicada pela primeira vez a ele por João Damasceno (a forma "malelas" surgiu pela primeira vez com o reinado de Constantino VII Porfirogênito).

4 Malalas (2000: 171). 
EC. Em 70 EC mudou-se para Roma, onde escreveu seus trabalhos à época dos flavianos. Os vestígios arqueológicos descobertos em alguns locais também fornecem detalhes importantes sobre as construções de Herodes, alguns corroborando os relatos do historiador, e outros acrescentando novas informações sobre os projetos do rei e os esforços para expor a população local da antiga Palestina a padrões culturais contemporâneos. Através de suas atividades, Herodes quis expressar sua lealdade ao imperador, integrar seu reino ao mundo romano e engrandecer seu nome entre seus súditos, vizinhos e patronos (Weiss 2014: 13).

Uma análise das evidências literárias e dos restos arqueológicos indica que o rei agiu de acordo com um programa bastante planejado. Segundo Zeev Weiss (2014: 13-14):

No curso de seu reinado, ergueu vários edifícios em vários locais (inaugurou celebrações em honra do imperador em alguns deles) $e$ realizou jogos nesses espaços periodicamente. Um novo ambiente cultural tomou forma e se estabeleceu ao longo do tempo. Monica Selvatici (2015: 179) informa que Herodes seguira os padrões de seu tempo, ou seja, tempos em que Augusto era Imperador de Roma, instituindo rapidamente os jogos olimpicos tanto em Cesareia como em Jerusalém.

Vários tipos de espetáculos e competições foram realizados em um festival que Herodes estabeleceu em Jerusalém em homenagem a Augusto, aparentemente na primavera ou no verão de $28 \mathrm{AEC}$. Esses eventos, que Josefo descreve em detalhe, foram realizados em vários edifícios que o rei construiu dentro da cidade:

Em primeiro lugar ele estabeleceu competições esportivas a cada cinco anos em homenagem a César e construiu um teatro em Jerusalém, e depois disso um anfiteatro muito grande na planície, ambos espetacularmente luxuosos, mas estranhos ao costume judaico. O uso de tais edifícios pelos judeus e sua exposição em tais espetáculos não têm sido usual. Herodes, no entanto, celebrou o festival quinquenal da forma mais esplêndida, enviando avisos para os povos vizinhos e convidando participantes de toda a nação. Atletas e outras classes de competidores foram convidados de todas as terras, sendo atraídos pela esperança de ganhar os prêmios e pela glória da vitória. E os principais homens em vários campos foram reunidos; Herodes ofereceu prêmios muito grandes não só para os vencedores dos jogos atléticos, mas também para aqueles envolvidos com música e representações, os chamados thymelikoi. E foi feito um esforço para que todas as pessoas mais famosas comparecessem ao concurso.

\section{Herodes também ofereceu presentes} consideráveis aos condutores de quadrigas e bigas e para cavaleiros que competiam em cavalos de corrida. Todos os esforços sempre caros ou magnificos que tinham sido feitos por outros governantes Herodes imitou em sua ambição de ver seus espetáculos tornarem-se famosos. Em todo o teatro havia inscrições dedicadas a César e troféus das nações que Herodes havia vencido na guerra, todos feitos para ele de ouro puro e prata. Quanto aos objetos viáveis, não havia vestimenta valiosa ou recipiente de pedras preciosas que não estivesse também exposto ao longo das competições. Havia também uma provisão de animais selvagens, um grande número de leões e outros animais que foram reunidos para ele, ou pela força extraordinária que tinham ou por serem muito raros. Quando começou a prática de envolvê-los em combate uns com os outros ou de colocar homens condenados para enfrentá-los, os estrangeiros ficaram surpresos $e$, ao mesmo tempo, entretidos com o perigoso espetáculo, mas para os locais isso significou um rompimento aberto com os costumes mantidos por eles. Pois parece impiedosa impiedade lançar homens a feras para o apelo de outros homens como espectadores, e parece uma impiedade ainda maior mudar seus modos estabelecidos para práticas estrangeiras. (Josephus 1998: 15.268-275, tradução minha)

Josefo relata que Herodes construiu um impressionante teatro e um grande anfiteatro 
em Jerusalém, onde realizou espetáculos e competições de vários tipos. Exceto por vários assentos de pedra pertencentes ao teatro, que ficavam em Jerusalém (seja de data herodiana ou da época de Adriano), esses dois edifícios que Herodes construiu ainda não foram descobertos na cidade, e Zeev Weiss (2014: 15) mostra uma quantidade enorme de autores cujas opiniões se dividem quanto à localização desses edifícios - se encontravam-se dentro da malha urbana ou não.

Os jogos em Jerusalém foram estabelecidos, como Josefo relata, como um festival quinquenal (realizado a cada cinco anos). Com a dedicação de Cesareia em 10 AEC, no 28 ano de governo de Herodes (que coincidiu com a 192a Olimpíada), o rei também inaugurou os jogos naquela cidade (Josephus 1997: 1.415; 1998: 16.136-140).

Herodes habilidosamente dedicou os jogos ao patrono Augusto em comemoração à vitória do imperador na batalha de Actium em 31 AEC. Josefo narra os acontecimentos em Cesareia em três de suas obras: Antiguidades Judaicas (Josephus 1998), Guerra dos Judeus contra os romanos (Josephus 1997) e Vida de Flavio Josefo (Josephus 2001). Em sua Guerra dos Judeus contra os romanos, Josefo menciona os edifícios, as competições e os prêmios dados aos participantes:

O resto dos edifícios (anfiteatro, teatro e lugares públicos) foi construído em um estilo digno do nome que a cidade tinha. Além disso, [Herodes] instituiu jogos quinquenais, também com o nome de César, e os inaugurou ele mesmo, oferecendo prêmios do mais alto valor; nesses jogos, não apenas os vencedores, mas também aqueles que obtiveram o segundo e o terceiro lugar participaram da recompensa real. (Josephus 1997: 1.415, tradução minha).

Junto com a descrição dos grandes projetos de Cesareia, Josefo menciona em suas Antiguidades Judaicas os edifícios e sua localização dentro da cidade: "Herodes também construiu um teatro de pedra na cidade e, no lado sul do porto, mais atrás, um anfiteatro grande o suficiente para abrigar uma grande multidão de pessoas e convenientemente situado para se obter uma visão do mar" (Josephus 1998: 15.341, tradução minha). Na mesma obra, Josefo enumera as competições que Herodes realizou na cidade após a conclusão das construções:

pois ele anunciou um concurso de música e de exercícios atléticos, e preparou um grande número de gladiadores e feras, e também corridas de cavalos e shows muito luxuosos que devem ser vistos em Roma e em vários outros lugares. Este concurso também ele dedicou a César, tendo o organizado para celebrá-lo a cada cinco anos. E César, acrescentando brilho ao seu amor e glória, enviou todos os equipamentos necessários para tais jogos de suas próprias receitas. Por sua própria conta, a esposa de César, Júlia, enviou muitos de seus maiores tesouros de Roma, de modo que a quantia inteira foi computada como nada menos que quinhentos talentos. (Josephus 1998: 16.137-140, tradução minha)

Os jogos e as competições realizados em homenagem a Augusto em Cesareia foram organizados em um formato semelhante ao de Jerusalém, a cada cinco anos; houve também em Cesareia combates de gladiadores e, como observa Josefo, os prêmios eram concedidos não apenas aos vencedores, mas também àqueles que terminaram em segundo e terceiro lugares.

Em Cesareia, restos de um teatro e de um anfiteatro foram descobertos na costa sul do porto (Fig. 1); no entanto, o nome "anfiteatro" usado por Josefo não está de acordo com a forma da estrutura descoberta naquele ponto. Essa incongruência, assim como o uso de vários termos para definir um único edifício em um lugar específico, também é recorrente em outros lugares em seus escritos.

O teatro de Cesareia foi construído ao sul da cidade de Herodes, na encosta oeste de uma colina rochosa de altura moderada voltada para o mar. Era de 90 metros de diâmetro e estima-se que dispusesse de cerca de 4 mil assentos. Diversos elementos arquitetônicos foram detectados nos restos preservados do edifício - cavea, ambulatorium e scaenae frons, com um recesso retangular em seu centro 
e nichos curvilíneos em ambos os lados. Antonio Frova et al., no trabalho Scavi di Caesarea Maritima, informam que os nichos semicirculares e retangulares no proscaenium foram posteriormente substituídos por uma fachada plana. O proscaenium em ambas as fases foi decorado com gesso pintado, assim como o piso da orquestra, cujas 14 camadas de gesso continham padrões florais e vegetais (Frova, 1966: 93-112, 128-145).

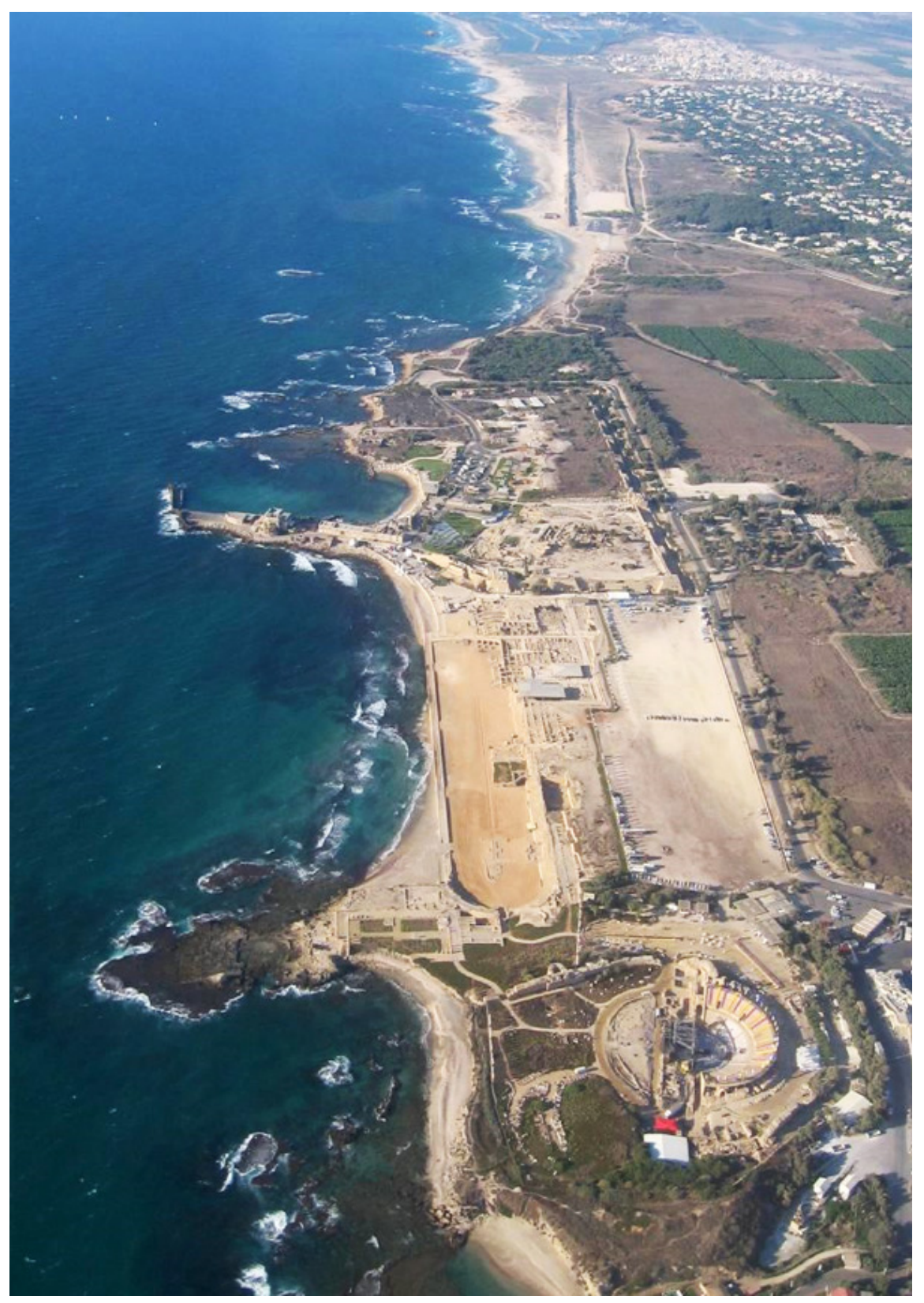

Fig. 1. Vista aérea de hipódromo-anfiteatro e do teatro de Cesareia.

Fonte: Wikimedia Commons (domínio público). Disponível em: 〈https://goo.gl/yVQctb〉. Acesso em: 31 jul. 2018. 


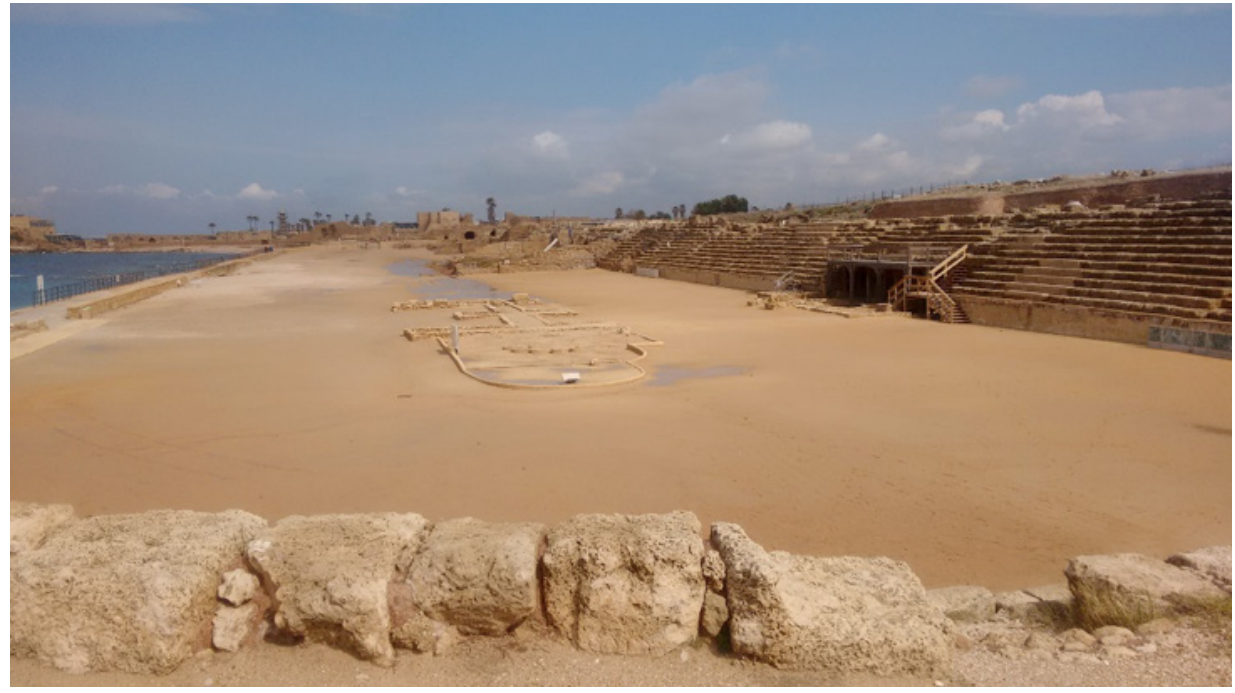

Fig. 2. Vista do Hipódromo de Cesareia.

Foto: Matheus Morais Cruz (2017).

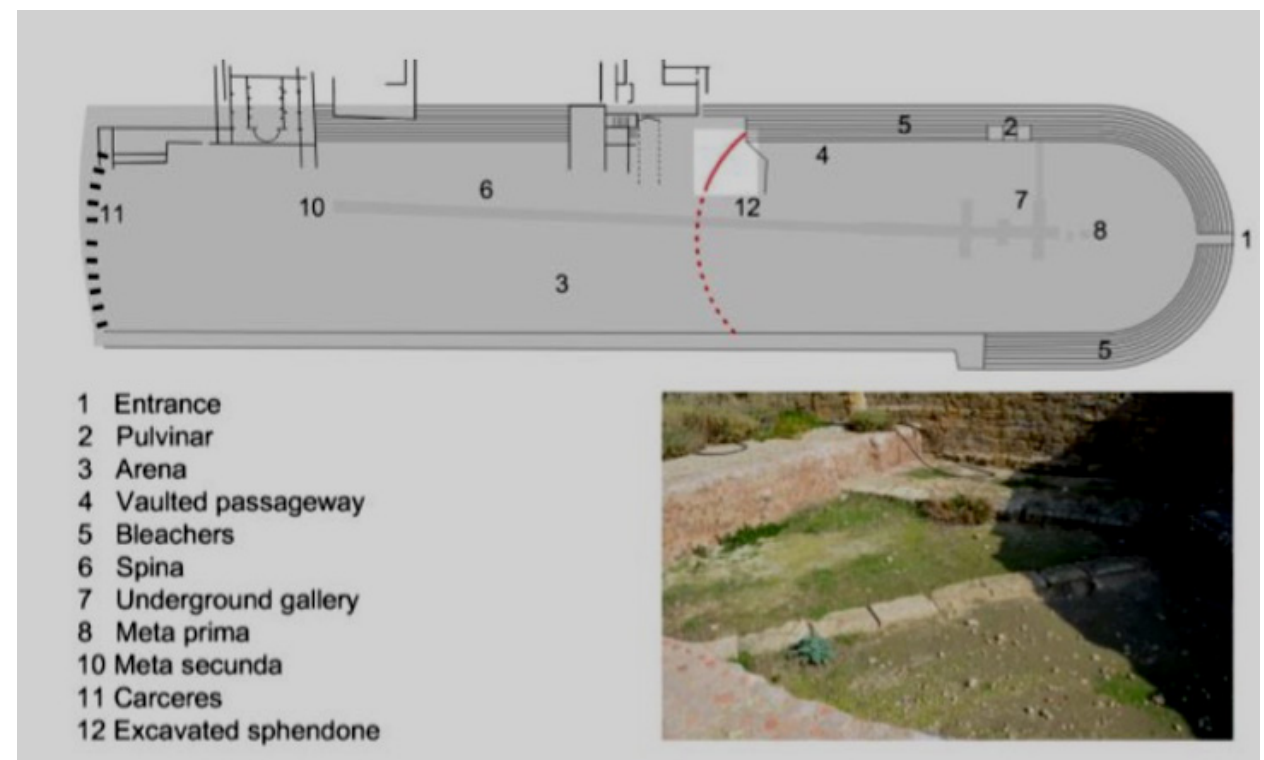

Fig. 3. Transformação tipológica do circo em anfiteatro em Cesareia Marítima. Um novo shendone foi adicionado (em vermelho), a fim de reduzir o dromos e convertê-lo em uma arena. 1. Entrada; 2. Pulvinar ${ }^{5}$; 3. Arena; 4. Passagem abobadada; 5. Arquibancadas; 6. Espina ${ }^{6}$; Meta prima; Meta secunda; Carceres; Sphendone escavado.

Fonte: Adembri (2015: 22).

5 Pulvinar era um banco elevado e conspícuo em que o patrocinador dos jogos (em latim: editor) geralmente se sentava ao lado das imagens dos deuses para assistirem aos espetáculos.

6 Espina (em latim: spina) ou espinha era a seção que ficava no meio do hipódromo, geralmente decorada por colunas, estátuas e obeliscos. Os pontos de virada nas duas extremidades da espina eram geralmente decorados por postes cônicos chamados metas. 
Entre o extremo sul do porto e a área próxima ao teatro ficava um monumental hipódromo de 10 mil assentos no eixo norte-sul, paralelo ao litoral (Fig. 2 e 3). O edifício que Josefo chamava de "anfiteatro" era uma estrutura retangular (medidas exteriores de cerca de $312 \times 69 \mathrm{~m}$ ) cuja curta extremidade sul formava um semicírculo (sphendone) e em cuja extremidade oposta ficavam os portões de largada (carceres) (Weiss 2014: 17). As filas de assentos foram construídas contra uma parede maciça de nove metros de espessura ao redor da arena $(300 \times 50 \mathrm{~m})$ (Porath 1995: 16).

No centro do sphendone do edifício havia um portão monumental, através do qual se entrava na arena e de lá se procedia para os assentos na cavea. A cavea tinha 12 fileiras de assentos dispostas em 18 niveis (12 dos quais ainda estão preservados), com escadas (scalaria) correndo entre os blocos (cunei). Uma caixa de tribunal (tribunal) foi construida na cavea oriental, no terço sul do edifício. Poucos vestígios foram encontrados do euripus - a barreira que percorre a arena que separa os dois lados da pista. Parece que este item era composto de vários elementos independentes que ficavam em uma linha, além de projetar colunas de madeira ou metal que indicavam aos cocheiros que eles estavam atingindo os pontos de virada (metae). Os carceres ou portões de largada no extremo norte do edificio foram restaurados três vezes durante o periodo herodiano. Eles tinham dez barracas, além do portão monumental no centro. (Weiss 2014: 17, tradução minha)

Josefo menciona explicitamente que Jerusalém e Cesareia são as únicas cidades nas quais o rei ergueu edifícios para os eventos e jogos públicos realizados uma vez a cada cinco anos. Esse não foi o caso de Jericó, onde Herodes construiu vários palácios durante seu reinado. Apenas perto de sua morte, em 4 $\mathrm{AEC}$, é que se ouve, pela primeira vez, sobre dois edifícios na cidade, mas Josefo não fornece nenhuma informação a seu respeito ou sobre os jogos e competições neles realizados.

Herodes reuniu as autoridades judaicas no anfiteatro (Josephus 1998: 17.161) depois que os jovens em Jerusalém removeram a águia do portão do Templo e, perto de sua morte, convocou notáveis judeus para Jericó e mandou-os calar no hipódromo (Josephus 1998: 17.174-178) ${ }^{7}$. Após a morte de Herodes, Salomé e seu marido, Alexas, dispensaram aqueles que haviam sido chamados para o hipódromo e reuniram os soldados no anfiteatro de Jericó (Josephus 1997: 1.666; 1998: 17.193-194). Assim, embora conste no relato de Josefo que em Jericó havia dois edifícios separados, os achados arqueológicos sugerem que, na verdade, tratava-se de uma única estrutura polivalente.

Um complexo multifuncional contendo um hipódromo, um teatro e outro prédio magnífico - um ginásio ou um palácio - foi descoberto em Tell es-Samarat, ao norte dos palácios de inverno de Herodes em Jericó e não muito longe daquela cidade antiga (Fig. 4). O hipódromo, construído em um eixo norte-sul, era retangular e media aproximadamente $315 \times 82$ metros. A arena não tinha euripus permanente nem bancos construídos para se sentar, mas parece ter sido cercada por colunatas onde os espectadores podiam ficar de pé ou se sentar em assentos portáteis durante as corridas.

Um teatro foi construído no extremo semicircular do norte do hipódromo - isto é, nas encostas do sul da colina Tell es-Samarat -, de onde se tinha uma excelente visão da arena e das corridas realizadas nela. $O$ teatro tinha um diâmetro de cerca de 70 metros e podia conter cerca de 3 mil lugares. De acordo com Weiss,

Apenas uma parede da cavea foi preservada, assim como a fundação abaixo dos assentos e partes da passagem entre as seções da cavea. O teatro não tinha palco permanente nem scaena, já que estes teriam bloqueado a visão dos espectadores sentados na cavea ao assistir as corridas na arena; parece que uma estrutura de madeira temporária era erguida ao sul da orquestra, quando necessário. Ao norte da cavea e adjacentes a ela, no topo da colina, estavam as fundações de um edifício elevado de $70 \mathrm{~m}^{2}$, decorado com afrescos. (Weiss 2014: 19-20 tradução minha)

7 Cf. Josephus (1997: 1.659). 


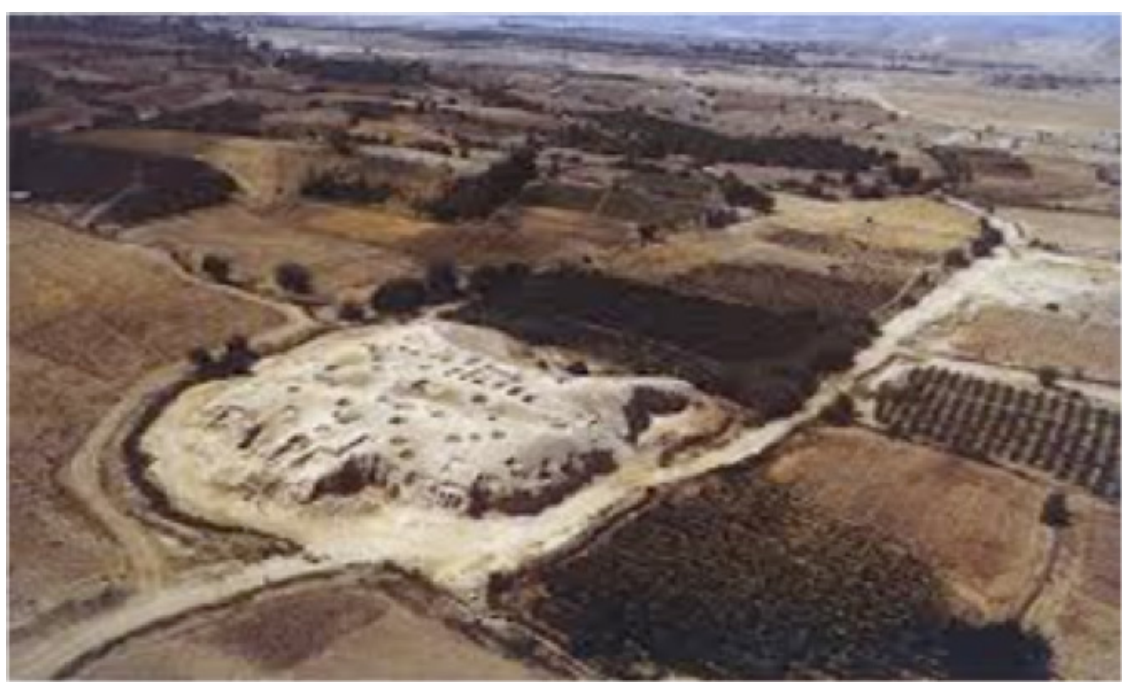

Fig. 4. Vista aérea do noroeste do complexo multifuncional em Jericó. No primeiro plano: restos do ginásio ou do palácio, o teatro em sua encosta sul e a pista de corridas do hipódromo na área cultivada.

Fonte: Weiss (2014: 21).

Segundo Weiss, o falecido Ehud Netzer, arqueólogo do prédio, afirmava que havia um pátio central cercado por colunas e salas de vários tamanhos ao norte. Josefo não menciona esses edifícios, e como a data dos fósseis arqueológicos é inconclusiva, não fica claro em qual fase Herodes os construiu - na segunda década do seu reinado ou, como Ehud Netzer sugeriu, em data posterior, perto da dedicação de Cesareia e das celebrações então realizadas na cidade (Netzer apud Weiss 2014: 20).

Benedetta Adembri et al. (2015: 21-22) mostram que esse tipo de adaptação ocorreu em outros lugares do Império, como é o caso do teatro de Lixus (Mauritânia romana), também convertido em um anfiteatro. Exemplar é o estádio de Afrodisias em Caria, onde uma espécie de pequeno anfiteatro dedicado a venationes foi construído em frente a um dos dois sphendonai (Welch 1998 apud Adembri 2015: 21).

Além dos projetos de construção de Herodes para entretenimento de massa em Jerusalém, Cesareia e Jericó, o rei-construtor também ergueu edifícios semelhantes em Samaria e Herodium; estes não são mencionados nos escritos de Josefo, mas foram descobertos em toda sua glória em escavações arqueológicas realizadas nesses locais. Após a batalha de Actium, e depois de Augusto ter concedido a Herodes territórios adicionais, incluindo a Samaria, este último decidiu provavelmente depois de $27 \mathrm{AEC}$ - construir a cidade e adorná-la com diversos edifícios a fim de ganhar o favor dos habitantes locais, nomeando-a Sebaste (nome em grego para "Augustus") em homenagem ao imperador. Herodes iniciou vários projetos de construção na cidade e, embora Josefo não mencione o estádio no vale, que foi cercado pelo muro herodiano na parte noroeste da cidade, sua construção é atribuída aos projetos de construção do rei (Josephus 1997: 1.403; 1998: 15.296-298).

O estádio é retangular $(205 \times 67 \mathrm{~m})$; um pátio em seu centro $(194 \times 58 \mathrm{~m})$ é cercado nos quatro lados por colunatas de estilo dórico, e suas paredes traseiras, que foram preservadas no sul, foram decoradas com afrescos (Weiss 2014: 20-22). Os painéis marcados com figuras grosseiras de pugilistas e lutadores, alguns segurando armas, retratam cenas de espetáculos realizados na arena. Ao lado deles estão várias inscrições em grego com nomes, alguns de origem latina, atestando a proveniência de alguns dos habitantes da cidade, incluindo veteranos militares. Uma das inscrições de data um pouco posterior, talvez entre 50 e $150 \mathrm{EC}$, pede a Core que se lembre por bem do mestre 
Jogos, espetáculos e competições na Palestina romana R. Museu Arq. Etn., 29: 119-136, 2017.

aprendiz Martialis e de seus amigos. Depreendese desta inscrição que palestras também foram realizadas no prédio, provavelmente na sombra e no frescor dos pórticos. As inscrições, os altares e as estátuas descobertos dentro e ao redor do estádio atestam a adoração cultual à Core, deusa da cidade, talvez já nos dias de Herodes, que lá construiu um templo dedicado a ela ${ }^{8}$.

Não longe de Jerusalém, um pequeno teatro foi descoberto em Herodium (Fig. 5), o palácio-fortaleza de Herodes e seu último local de sepultamento (Josephus 1997: 1.670-673).

O prédio foi construído por volta de 26 AEC, talhado parcialmente em substrato rochoso não muito longe do mausoléu do rei. Media 32 metros de diâmetro e possuía aproximadamente de trezentos a quatrocentos assentos. A cavea continha doze filas de assentos divididos em dois blocos horizontais: a zona inferior continha três cunei, e a superior, quatro. No topo da cavea havia uma colunata com três câmaras atrás dela. A câmara central e mais espaçosa $(8 \times 7 \mathrm{~m})$ foi decorada com afrescos contendo padrões figurativos que se assemelham aos encontrados na Campânia a partir dos anos 20 do século I AEC - data estimada para a última etapa do teatro e de sua decoração. (Weiss 2014: 22-23, tradução minha)

Aparentemente não era fácil assistir às performances que ocorriam no palco dessa câmara; Zeev Weiss (2014: 23) sugere que este era um pequeno cômodo real destinado a reuniões íntimas ou eventos privados do rei e de seus amigos próximos. As entradas laterais davam acesso à orquestra, e a riqueza do palco em frente à cavea é atestada por seus muitos elementos arquitetônicos, alguns decorados com afrescos, descobertos nos destroços.

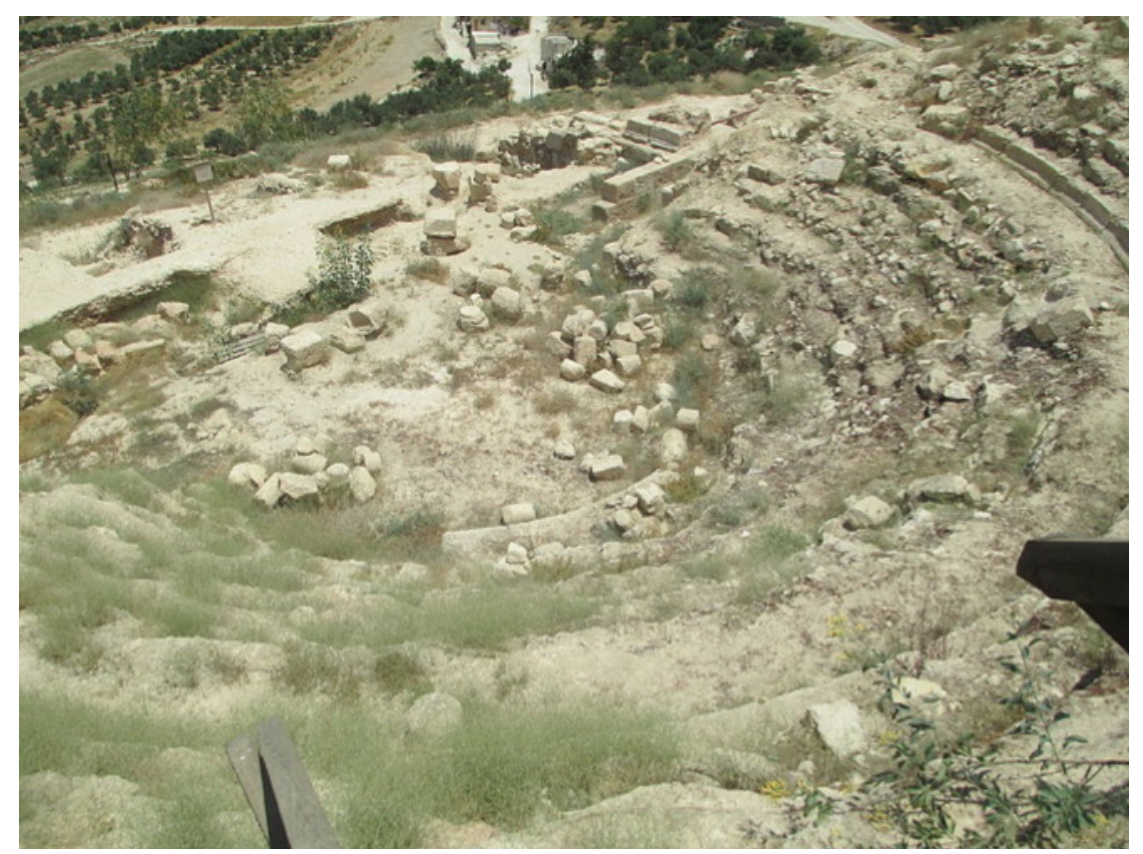

Fig. 5. Vista aérea do teatro de Herodium.

Fonte: Wikimedia Commons (domínio público). Disponível em: 〈https://goo.gl/mX3hRH>. Acesso em: 31 jul. 2018. 
O diverso programa de jogos inaugurado por Herodes e a forma arquitetônica dos edifícios que ele ergueu são típicos dos projetos do rei. Apesar de, de fato, corresponderem à terminologia variada de Josefo, permanece alguma confusão em relação aos nomes e aos propósitos de alguns dos edifícios.

\section{Os vários tipos e uso dos edifícios}

A variedade de competições e espetáculos que Herodes realizou em Jerusalém e Cesareia competições atléticas, corridas de cavalos e bigas, música e palco para confraternizações, além de demonstrações de lutas de animais e combates entre gladiadores - parece ter exigido a construção de quatro diferentes estruturas em cada cidade: um estádio, um hipódromo, um teatro e um anfiteatro, para seus diferentes usos, respectivamente ${ }^{9}$. Josefo escreveu que Herodes aparentemente construiu um teatro e um anfiteatro ou hipódromo - mas não um estádio - em Jerusalém, na Cesareia e, muito provavelmente, em Jericó, embora o historiador não diga isso explicitamente. Com o rei morto, e no período seguinte, Josefo menciona monumentos adicionais que ficaram em Jerusalém e Cesareia que não estão listados entre projetos de construção de Herodes. Por exemplo, um dos grupos que participaram dos tumultos em Jerusalém após a morte de Herodes se abrigou no hipódromo ao sul do Monte do Templo (Josephus 1997: 2.43-44; 1998: 17.254-255), e Pôncio Pilatos se encontrou no estádio de Cesareia com judeus de Jerusalém que imploravam a ele para remover bustos do imperador que estavam ligados aos padrões do exército, pois tais figurações eram proibidas pela lei judaica (Josephus 1997: 2.172-174; 1998: 18.57-59). Apesar de a construção do hipódromo em Jerusalém ou do estádio em Cesareia não ser atribuída a Herodes, e uma vez que não se pode atribuir projetos arquitetônicos a qualquer outra figura na época, queremos crer - assim

9 Segundo Weiss (2014: 24), Schürer acredita que existiram quatro construções em Cesareia, enquanto Schalit sugere que foram erigidos três edifícios em Jericó. como argumenta Zeev Weiss (2014: 24) -, ou as informações cumulativas nos obrigam a assumir, que Herodes era responsável por sua construção também; soma-se a isso que é evidente que o rei precisava desses edifícios para os vários jogos que instituiu.

É difícil imaginar que, além de outros monumentos nessas cidades, Herodes tenha ainda erigido três edifícios impressionantes para abrigar uma variedade de apresentações. Esses empreendimentos eram caríssimos até mesmo para Herodes, conhecido por sua generosidade (liberalitas Augusti). Além disso, não havia espaço suficiente em cada cidade para três dessas estruturas.

Quanto a Jericó, pode-se supor que o "hipódromo" e o "anfiteatro" mencionados nas obras de Josefo se referem às várias partes do complexo multifuncional descoberto na cidade, ao norte do palácio de Herodes. Por exemplo, a arena no hipódromo ou estádio à qual alguns judeus notáveis foram conduzidos, aguardando a morte, era de fato um lugar adequado para se fazer isso, assim como Pilatos ameaçou fazer com os habitantes de Jerusalém e como Vespasiano mais tarde fez com o povo de Tarichaeae (Magdala) ${ }^{10}$. Os soldados que se reuniram no teatro ${ }^{11}$ provavelmente se sentaram na cavea enquanto Salomé e Alexas estavam em frente a eles na orquestra, lendo a carta de Herodes em voz alta, assim como Ptolomeu fez ao ler a vontade do rei para eles ou como Herodes fez quando repreendeu os líderes judeus após a remoção da água do templo (Josephus 1998: 17.155-163). Mesmo que esses termos não se refiram a várias partes do edifício, Josefo estava se referindo a um mesmo edifício em Jericó quando o chamou de hipódromo e, posteriormente, de anfiteatro.

Os achados arqueológicos indicam que Herodes não construiu anfiteatros ovais monumentais como os encontrados em todo

10 Sobre Pilatos, ver Jewish antiquities (Josephus 1998: 18.57); The Jewish war (Josephus 1997: 2.172-174). Sobre Vespasiano, ver The Jewish war (Josephus 1997: 3.539-540).

11 Josefo chamou essa estrutura de anfiteatro (Josephus 1998: 17.161). 
o resto do império. Portanto não está claro por que Josefo usou o termo "anfiteatro" ao descrever os projetos do rei e a que tipo de edifício ele estava se referindo. Esse ponto difícil é elaborado aqui não apenas porque o rei precisava de um edifício específico para realizar competições atléticas e corridas de bigas, mas porque um hipódromo em Cesareia foi descoberto no mesmo local em que, de acordo com Josefo, havia um anfiteatro. John H. Humphrey (1996: 121-122) alude ao fato de que Josefo não cometeu nenhum erro na identificação dos edifícios e não confundiu seus nomes: o termo "anfiteatro", em seu tempo, também se referia ao hipódromo ou ao estádio onde os espectadores ficavam sentados em torno de uma arena.

Weiss (2014: 27) lembra que o edifício oval - o primeiro bem conhecido anfiteatro romano construído à distância do Fórum no final da República e no início do Império - recebeu o nome latino spectacula (uma abreviação de spectacula gladiatorum ou spectacula gladiatorii muneris). Ao descrever os monumentos herodianos em Cesareia e em outros lugares, Josefo usou a terminologia aceita de seu dia, "anfiteatro", para descrever o edifício alongado com assentos ao redor (isto é, o hipódromo/ estádio) e distingui-lo do teatro próximo, onde os assentos estavam dispostos em semicírculo.

O edifício em Cesareia é um bom exemplo de seus múltiplos propósitos. $\mathrm{O}$ comprimento da pista corresponde ao que era necessário para as competições atléticas, e as dimensões do interior do edifício - comprimento e especialmente largura - eram suficientes para a realização de corridas de bigas. $\mathrm{O}$ euripus correndo pelo centro da pista era feito de tal maneira que poderia ser removido para competições de corrida, enquanto as baias dos carceres foram projetadas especialmente para corridas de cavalos e bigas. Os combates de gladiadores e a caça de animais (condenando à morte animais ou seres humanos) também foram realizados na arena; isso é indiretamente corroborado pelos buracos encontrados no topo do pódio ao longo de toda a cavea oriental, que deveriam acomodar postes de madeira que sustentam redes para proteger os espectadores dos animais selvagens que corriam livremente na arena ${ }^{12}$.

Várias fontes na literatura talmúdica, principalmente tradições antigas, referem-se ao hipódromo/estádio como uma estrutura multiuso que também realizou apresentações "anfiteatrais". Uma lei tanaítica estabelece que os judeus não tinham permissão para vender ursos ou leões a não judeus para apresentações no estádio (Steinsaltz 2001: 1, 7). A decisão da Mishná, segundo a qual os touros inclinados a ferir as pessoas deveriam ser condenados à morte, serviu de engodo e abriu uma exceção em relação aos touros usados em espetáculos no estádio (Guggenheimer 2009: 4, 4).

Cashdan (1965) informa que no início do segundo século, R. Nathan ${ }^{13}$ permitiu a participação em combates de gladiadores no estádio, que envolviam judeus condenados à morte, apenas porque os espectadores judeus "clamam para salvar a vida [dos derrotados] $e$ porque eles podem testemunhar em nome de uma mulher [cujo marido foi morto na luta] para que ela possa se casar novamente" (Steinsaltz 2001: 2, 7, tradução minha).

12 Zeev Weiss (2014: 28) nos afirma que em vários locais em que se tinham jogos gladiatórios que envolviam animais selvagens adicionavam-se redes para a proteção dos espectadores. Para saber mais, veja Golvin (1988). Em matéria de segurança em espetáculos de gladiadores e lutas de animais na arena, ver Alex Scobie (1988). Este autor afirma que a rede era colocada no chão da arena a cerca de dois metros ou mais do pódio, e não no topo. Portanto os espectadores na cavea desfrutavam de dupla proteção.

13 Avot de-Rabbi Nathan (em hebraico: ותנ יברד תובא), geralmente impresso junto com os tratados menores do Talmud, é um trabalho judaico hagádico provavelmente compilado na Era Geônica (c. 700-900 EC). Embora Avot de-Rabbi Nathan seja o primeiro e mais longo dos "tratados menores”, provavelmente não pertence cronologicamente àquela coleção, tendo mais o caráter de um midrash tardio. Na forma agora existente, contém uma mistura de Mishnah e Midrash, e pode ser tecnicamente designado como uma exposição homilética do tratado Mishnaic Pirkei Avot, tendo para sua fundação uma versão mais antiga daquele tratado. Pode ser considerado como uma espécie de "tosefta" ou "gemarah" para o Mishna Avot, que não possui um gemarah tradicional. Avot de-Rabbi Nathan contém muitas frases, provérbios e incidentes que não são encontrados em nenhum outro lugar na literatura rabínica inicial (Cashdan 1965). Outros ditados rabínicos aparecem em um estilo mais informal do que o que é encontrado no canônico Mishna Avot redigido por Judá I. 
As fontes à nossa disposição indicam, portanto, não apenas que o hipódromo/ estádio era uma estrutura polivalente, mas também que seu uso foi bastante comum mesmo após a era herodiana.

\section{Festivais e competições nos dias de Herodes}

Com a construção de vários edifícios monumentais para entretenimento público em todo o seu reino, seja em seus palácios particulares ou dentro da matriz urbana, Herodes, o Grande, teve sucesso na mudança dos hábitos culturais da população local.

O rei não começou com um ou dois tipos de espetáculos e, gradualmente, adicionou vários outros; em vez disso, a impressão que Josefo nos passa é que, desde o início, Herodes apresentou a seus súditos as mesmas competições públicas e performances conhecidas em outras partes do império.

Segundo David Potter (1999: 256-257), de um modo geral, havia quatro categorias diferentes de espetáculos públicos no mundo romano - competições agonísticas, corridas de circo, espetáculos teatrais e espetáculos anfiteatrais. Os espetáculos apresentados por Herodes em Jerusalém e Cesareia tinham, cada um a seu próprio modo, extensão e formato, e podiam ser iniciados e conduzidos em diversas ocasiões.

Segundo Zeev Weiss (2014: 29), cada cidade grega deveria realizar ao menos um festival em homenagem a sua divindade local e incluir uma procissão, um sacrifício e competições agonísticas (esportes de combate, corridas à distância e alguns outros esportes competitivos), competições nas artes cênicas (música, drama e retórica) e, em algumas ocasiões, também, corridas de cavalos e carruagens. Estes seguiam a tradição dos jogos pan-helênicos, que ocorriam a cada quatro anos, como era o caso de Olímpia, Delfos, Istmo e Nemeia. Vários outros jogos, como os jogos ácios (instituídos inicialmente para celebrar a vitória de Otaviano sobre Marco Antônio e Cleópatra), foram adicionados mais tarde. $\mathrm{O}$ vencedor dos "jogos da coroa sagrada" (agônes hieroi kai stephanitai) recebia uma coroa de louros ou uma coroa. Quando o vencedor retornava a sua cidade natal, era recebido por uma procissão (eiselastikos) em sua homenagem, bem como com recompensas materiais pela honra que trouxera para sua cidade.

As cidades gregas do Oriente, de modo geral, logo desejaram realizar competições similares. Isto fez com que surgissem festivais e jogos adicionais em todo o Oriente Romano; depois de receber a aprovação do imperador, os jogos obtinham reconhecimento oficial de todas as cidades e, como ocorria nos jogos gregos mais antigos, cada cidade participava com seus melhores atletas. $O$ programa e os prêmios nesses jogos imitavam o formato dos que existiam nos grandes centros pan-helênicos, e essas cidades até declararam seus jogos como festivais isolimpicos ou isopiticos, que eram literalmente equivalentes aos jogos olímpicos ou píticos que ocorriam em Delfos (Weiss 2014: 30).

Outros festivais e jogos realizados em outras partes do império foram os "jogos de prêmios" (agônes thematikoi), nos quais os ganhadores recebiam dinheiro ou outros prêmios valiosos. Às vezes atraindo competidores de primeira linha, esses jogos eram realizados com mais frequência e aumentaram em número ao longo do tempo. Além do prêmio, o programa desses jogos era idêntico ao dos "jogos sagrados da coroa". Nesses casos, a cidade podia decidir se limitaria as competições à população local ou se convidaria candidatos de fora da cidade. Os jogos eram realizados para comemorar um evento histórico, para homenagear reis e imperadores, deuses da cidade ou até mesmo magistrados locais que, ao entrarem no escritório, financiavam os jogos às suas próprias custas (Weiss 2014: 30).

Michael J. Carter (2014: 622) apresenta o estereótipo que seduziu por muito tempo os estudiosos modernos: a ideia de que existia uma importante divisão entre "esportes" e "espetáculos" entre os gregos e os romanos. Os gregos dariam à palavra esporte o sentido de competições físicas entre atletas que concorriam por simples coroas de flores para mostrar sua excelência (aretê). Os romanos preferiam o espetáculo sem valor que era oferecido à 
população com comida e destreza sem sentido (como no famoso panem et circences de Juvenal (1996: 130, 10.81). O esporte é bom; o espetáculo é ruim. Esse estereótipo apontado por Carter não se verificava no mundo grego ou romano - inclua-se aí a Palestina de época herodiana. Aquela região estava permeada pelo emaranhamento cultural que amalgamava ao mesmo tempo expressões culturais de gregos, judeus, romanos, dentre tantos outros grupos, e à sua frente estava Herodes, o rei-construtor que era a expressão maior desse grande caldeirão cultural que foi o Oriente daqueles tempos.

Em 134 EC, Adriano propôs que os festivais fossem coordenados com a passagem de quatro anos de competições no circuito internacional principal, para que não entrassem em choque com as festividades conhecidas e outros eventos importantes no caminho. Além disso, ele ordenou que as coroas e os saquinhos de dinheiro em todos os jogos fossem sempre exibidos abertamente em uma mesa para que todos pudessem ver e que um oficial imperial verificasse que o dinheiro estava onde deveria estar. Embora nenhuma cidade da antiga Palestina ou da Arábia seja mencionada nas cartas de Adriano, sugeriu-se que a ordenação de tais eventos fosse administrada nas maiores cidades do Oriente Romano, enquanto outros jogos eram realizados apenas em um circuito mais local (Slater 2008: 610-620 apud Weiss 2014, 30).

Cavalos e particularmente corridas de bigas, competições populares no mundo romano, eram frequentemente realizadas fora da infraestrutura de atletismo cívico. A maioria das corridas incluía a quadriga conduzida por um único cavaleiro, mas o programa do dia às vezes usava a biga ou a triga.

Bela I. Sandor (2012: 479-480) nos informa que os carros eram feitos de materiais perecíveis - madeira, pele crua, cola e muito pouco metal - para atingir uma alta aceleração e manter sua velocidade. Dez ou doze bigas participavam da corrida, dependendo do número de barracas nos portões iniciais do hipódromo. Várias dessas corridas (variando em número de lugar para lugar) eram realizadas a cada dia e continuavam até o anoitecer.
Enquanto a lista de competições teatrais realizadas durante os festivais tradicionais incluía várias formas de entretenimento, eles também apresentavam solistas estrelas em vários reinos - poetas, artistas corais, cantores acompanhados de liras, intérpretes de poemas épicos e outros atores. Juntamente com as competições nas artes cênicas, os romanos forneciam entretenimento em seus teatros que era puro divertimento. Comédias clássicas, tragédias e sátiras raramente eram encenadas no teatro romano com regularidade; em vez disso, mímicos, pantomimas e outras performances de inclinação mais leve eram muito populares na Roma imperial (Beacham 1991 apud Weiss 2014: 31).

Exibições aquáticas, como as do Maiuma, um festival noturno greco-sírio que ocorria no mês de maio, com peças teatrais de dança ou mímica, estavam na moda em várias cidades do lado Oriental do Império (Bouchier 2015: 223-224).

Em contraste com os impérios originários do mundo grego que foram descritos até agora, os espetáculos anfiteatrais foram introduzidos e desenvolvidos no Ocidente latino e eram particularmente populares no período romano. Eles incluíam uma variedade de combates públicos entre dois animais, entre animal e homem, e entre dois homens. Os combates de gladiadores eram um espetáculo competitivo entre dois indivíduos, um pouco parecido com o esporte de combate grego, no qual o vencedor recebia um prêmio monetário, embora aqui o sangue às vezes fosse derramado na arena e a luta terminasse com a morte de um combatente. Munidos com uma variedade de armas, os combatentes lutavam entre si ou caçavam animais exóticos na arena. Esses espetáculos, assim como algumas das atrações cênicas ou corridas de bigas, eram algumas vezes conduzidos em conjunto com outros eventos públicos e pretendiam divertir as massas.

\section{Considerações finais}

Que tipos de espetáculos, então, foram realizados durante a vida de Herodes, o Grande? 
Qual foi a orientação cultural que ele estabeleceu na antiga Palestina e foi seguida após a morte do rei por outras cidades iniciando competições e performances similares para as massas? Tornase evidentemente claro pelas descrições de Josefo que o modelo para os jogos quinquenais realizados em Jerusalém e Cesareia foi retirado dos mundos grego e romano, levando Herodes a criar um evento combinado, muitas vezes resultando em algo diferentemente novo, como numa espécie de antropofagia cultural.

O programa dos jogos baseava-se em grande parte na tradição helênica, que incluía competições esportivas, corridas de carroças e performances artísticas nas quais, pela primeira vez, Herodes também incluía espetáculos romanos. Estas foram conduzidas no formato de agônes thematikoi (jogos de prêmios), nos quais os vencedores recebiam dinheiro ou outros prêmios valiosos (Weiss 2014: 32).

Isso era costumeiro em Jerusalém, e Josefo nos conta que Herodes deu prêmios "não apenas aos vencedores dos jogos de ginástica, mas também aos envolvidos em música e àqueles que são chamados de thymelikoi. Também ofereceu doações consideráveis aos cocheiros de carros de quatro ou dois cavalos e aos montados em cavalos de corrida" (Josephus 1998: 15.270271, tradução minha).

Josefo lista uma gama de performances e competições realizadas em Jerusalém e Cesareia. Embora a descrição de Jerusalém seja mais elaborada, é de se acreditar que o programa de jogos nas duas cidades deveria ser semelhante ${ }^{14}$. O historiador menciona as três categorias de competições realizadas na tradição helênica - eventos esportivos, artes cênicas e corridas de bigas -, mas praticamente não fornece informações sobre os tipos de disputas correspondentes às idades dos competidores, a disciplina dos jogos olímpicos e o número de competições e de participantes em cada grupo de eventos. As competições atléticas provavelmente seguiram o programa de outros "jogos sagrados" pan-helênicos, em que os atletas eram divididos

14 Jerusalém: Jewish antiquities (Josephus 1998: 15.268-275). Cesareia: Jewish antiquities (Josephus 1998: 16.136-141; The Jewish war (Josephus 1997: 1.415). por faixa etária - crianças, meninos e adultos para competir em eventos de corrida de longa distância, pentatlo, luta livre, boxe e pancrácio ${ }^{15}$.

Competições para músicos e thymelikoi foram realizadas nos teatros de Jerusalém e Cesareia, e em outras cidades também, embora Josefo não as mencionasse explicitamente. Ele usa o termo thymelikoi, mas a natureza exata da competição em si não é clara, uma vez que o significado dessa palavra mudou em função do tempo e do lugar. $\mathrm{Na}$ era helênica, thymelikos agôn referiase a uma competição musical, enquanto na época romana também incluía danças e palco para competições (Weiss 2014: 32-33). Vitrúvio indica que no teatro grego thymelikoi se apresentavam na orquestra, e não no palco, onde os atores trágicos e cômicos geralmente apareciam (Vitruvius 1970: 5.7.2).

No entanto, como a orquestra no teatro romano era parcialmente ocupada por dignitários, os thymelikoi, como todos os outros atores, atuavam no palco (Robert 1939 apud Weiss 2014: 33). Em relação à antiga Palestina, Josefo enumera uma série de músicos e thymelikoi, o que sugere que Herodes tinha dois tipos de competições - uma para músicos e outra para artistas que tocavam peças dramáticas; no entanto, o historiador não fornece detalhes adicionais sobre a natureza desses espetáculos ou exatamente onde ocorreram dentro do teatro.

Performances semelhantes foram incluídas nas festividades que Agripa I realizou no teatro de Cesareia em homenagem a Augusto, mas Josefo coloca esses eventos sob a rubrica dos theorriai ${ }^{16}$ (Josephus 1998: 19.343).

15 Pancrácio foi uma antiga arte marcial e um antigo desporto de combate sem armas que, segundo a mitologia grega, teve início com os heróis Héracles e Teseu. Uma mistura de boxe clássico e luta olímpica com golpes e técnicas de lutas que incluem socos, chutes, cotoveladas, joelhadas, cabeçadas, estrangulamentos, agarramentos, quedas, arremessos, derrubadas, imobilizações, torções, chaves e travamento das articulações.

16 Theōriai é o nome geral para os espetáculos teatrais e é frequentemente visto em inscrições dedicatórias da era imperial. 
As descrições de Josefo sobre as corridas de cavalos e carruagens são apenas um pouco mais detalhadas. Nelas, ele observa que Herodes realizou duas dessas competições - corridas de cavalos - e duas ou quatro corridas de bigas puxadas por cavalos.

Herodes também realizou performances anfiteatrais que se assemelhavam àquelas originadas no mundo romano, e parece que ele foi o primeiro a incluí-las nos jogos helênicos (Weiss 2014: 33). Josefo nos conta que em Jerusalém "havia também um suprimento de animais selvagens; muitos leões e outros animais foram reunidos para ele, por possuirem força extraordinária ou por serem tipos muito raros" (Josephus 1998: 15.273-274, tradução minha). Na arena de Jerusalém, os animais lutavam uns com os outros ou com humanos condenados até a morte, e em Cesareia houve até mesmo combates de gladiadores (Josephus 1998: 16.137). Com base em outras fontes mencionadas anteriormente, parece que, desde o período herodiano, não apenas leões, mas também touros, ursos e lobos foram usados em semelhantes performances mantidas nas arenas da antiga Palestina.

A singularidade dos jogos herodianos reside no fato de que, como observado, eles combinaram dois tipos de eventos. Embora maior ênfase tenha sido dada à tradição helênica, os combates de gladiadores no estilo romano e as lutas de animais também foram incluídos no repertório de obras mostradas em Jerusalém e Cesareia. A atividade de Herodes parece ser o exemplo mais antigo dessa iniciativa.

As descobertas arqueológicas, epigráficas e artísticas da Ásia Menor e da Grécia nos informam que tanto as competições anfiteatrais quanto as competições atléticas tornaram-se parte do culto imperial em seus estádios não antes do primeiro século EC. (Weiss 2014: 34). $\mathrm{Na}$ Síria romana também, segundo relato de Malalas, os combates de gladiadores foram incluídos no programa dos jogos olímpicos realizados em Antioquia durante o reinado de Cláudio em 43/44 EC, mas não antes (Malalas 2000: 10.27).

Assim, parece que Herodes pode ter sido o primeiro a introduzir um novo formato integrando o Oriente e o Ocidente nos jogos que fundou em Jerusalém e Cesareia, e parece que outras cidades do Oriente Romano subsequentemente seguiram seu exemplo. No entanto, o "ambiente que estava sendo criado instantaneamente" por Herodes, o Grande, para usar uma frase cunhada por Fergus Millar (1993: 353-356, tradução minha), era predominantemente grego e também foi adotado pela população local.

PORTO, V.C. Games, spetacles and competitions in Roman Palestine. R. Museu Arq. Etn., 29: 119-136, 2017.

Abstract: This article aims to present the games and competitions that were held in Roman Palestine. The following paragraphs will present the different constructions of Herod the Great, also known as king-builder, in the field of spectacles. Herod's Liberalitas Augusti, his generosity, and the insertion of romanitas in the region, especially through his constructions, will be highlighted. The paths of knowledge about the structures related to the games in Roman Palestine will be dictated by textual and material documentation, whether through its theatres, amphitheaters and hippodromes, or through cultural habits derived from these activities.

Keywords: Games; Competitions; Spectacles; Herod the Great; Roman Palestine. 


\section{Referências bibliográficas}

Adembri, B. et al. 2015. Reverse designing: an integrated method for interpreting ancient architecture. Scires 5 (2): 15-32.

Carter, M.J. 2014. Romanization through Spectacle in the Greek East. In: (Ed.) Christesen, P. \& Kyle, D.G. A Companion to Sport and Spectacle in Greek and Roman Antiquity, Wiley-Blackwell, Chichester, West Sussex, UK.

Cashdan, E. 1965. Introduction. In: A. Cohen (Ed.) The Minor Tractates of the Talmud: Massektoth Ketannoth, Volume I, Soncino Press, London.

Frazão José, N. 2014. Imagem e poder: considerações iniciais acerca das imagens discursivas sobre Augusto nas biografias e histórias do principado romano (séculos I a.C. a III d.C.). De Rebus Antiquis 4 (4): 78-99.

Frova, A. et al. 1966. Scavi di Caesarea Maritima. "L'Erma" di Bretschneider, Roma.

Golvin, J-C. 1988. L’amphithéâtre romain: essai sur la théorisation de sa forme et de ses fonctions. Diffusion de Boccard, Paris, v. 1, 317-318.

Gonçalves, A.T.M. 2013. Festas nos governos de Septímio Severo e Caracala: os jogos decenais. In: Cerqueira, F.V. et al. (Orgs.). Saberes e poderes no mundo antigo: estudos ibero-latino-americanos. Impressa da Universidade de Coimbra, Coimbra, v. 1., 229-240.

Guggenheimer, H.W. 2009. The Jerusalem Talmud. Fourth Order: Neziqin. Tractates Bava Qamma, Bava Mesia, and Bava Batra. Studia Judaica 45, Polytechnic University, Brooklyn, New York.

Humphrey, J.H. 1986. Roman circuses: arenas for chariot racing. B. T. Batsford, London.

Humphrey, J.H. 1996. 'Amphitheatrical' Hippo-Stadia. In: Raban, A.; Holum, K.G. (Eds.). Caesarea Maritima: retrospective after two millennia. Brill, Leiden, 121-129.
Josephus, F. 1997. The Jewish war. Translation H. St. Thackeray. Harvard University, London.

Josephus, F. 1998. Jewish antiquities. Translation Ralph Marcus. Harvard University, London.

Josephus, F. 2001. Life of Josephus. Translation Steve Mason. Brill, Leiden.

Juvenal. 1996. Sátiras. Traducción, Estudio y notas de Bartolomé Segura Ramos, Consejo Superior de Investigaciones Científicas, Madrid.

Magness, J. 2001. The cults of Isis and Kore at Samaria-Sebaste in the Hellenistic and Roman periods. HTR 94 (2): 157-177.

Malalas, I. 2000. Chronographia. Organization by Ioannes Thurn. De Gruyter, Berlin.

Millar, F. 1993. The Roman Near East, 31 BC-AC 337. Harvard University, Cambridge.

Netzer, E. 2006. The architecture of Herod, the Great Builder. Mohr Siebeck, Tübingen, 218-240.

Porath, Y. 1995. Herod's 'Amphitheatre' at Caesarea: a multipurpose entertainment building. In: Humphrey. J.H. (Ed.). The Roman and Byzantine Near East: some recent archaeological research. Journal of Roman Archaeology, Ann Arbor, supplementary series 14, 15-27.

Porto, V.C. 2018. O culto imperial e as moedas do Império Romano. Phoînix 24 (1): 138-154.

Potter, D.S. 1999. Entertainers in the Roman Empire. In: Potter, D.S.; Mattingly, D.J. (Eds.). Life, death, and entertainment in the Roman Empire. University of Michigan, Ann Arbor, 256-325.

Richardson, P. 1996. Herod: king of the Jews and friend of the Romans. University of South Carolina, Columbia, 174-202. 
Sandor, B.I. 2012. The genesis and performance characteristics of Roman chariots. JRA 25: 475-485.

Scobie, A. 1988. Spectator security and comfort at gladiatorial games. Nikephoros 1: 191-243.

Selvatici, M. 2015. História e arqueologia no estudo da economia da cidade de Jerusalém no século I d.C. Classica 28 (1): 177-192.

Steinsaltz, A. 2001. M Avodah Zarah. Talmud. Commentary, Translation, and Vocalization by Rabbi Adin Even-Israel (Steinsaltz). Israel Institute for Talmudic Publications, Jerusalém.
Suetônio. 2007. Vita diui Augusti. In: Suetônio; Augusto. A vida e os feitos do Divino Augusto. Tradução Matheus Trevizam, Paulo S. Vasconcelos e Antônio M. de Rezende. UFMG, Belo Horizonte, 9-115.

Vitruvius. 1970. De architectura. Translation Frank Granger. Harvard University, Cambridge.

Weiss, Z. 2007. Josephus and archaeology on the cities of the Galilee. In: Rodgers, Z. (Ed.). Making history: Josephus and historical method. Brill, Leiden, 387-414.

Weiss, Z. 2014. Public spectacles in Roman and late antique Palestine. Harvard University, Cambridge. 